\title{
Power ultrasound aided batter mixing for sponge cake batter.
}

\begin{abstract}
A high power ultrasound bath system has been used as a processing aid during sponge cake batter mixing in enhancing the mixing process to produce better quality of cake texture. The formulation for loading of 3 sponge cakes was mixed for 9 min at $90 \mathrm{rpm}$ under different combinations of ultrasound power exposure ranging from 1 to $2.5 \mathrm{~kW}$, and for duration ranging from 3 to $9 \mathrm{~min}$. The ultrasound was able to enhance the mixing process by resulting in lower batter density and flow behavior index, higher overrun and viscosity compared to the non-aided mixing. With the $2.5 \mathrm{~kW}$ ultrasound assisted mixing for entire batter mixing of 9 min, a better cake quality was produced in terms of lower cake hardness, and higher cake springiness, cohesiveness and resilience. The aided ultrasound power and duration during cake batter mixing showed more significant effects on cake properties than its batter properties.
\end{abstract}

Keyword: Ultrasound; Sponge cakes; Batter mixing; Aeration. 